\title{
Conservation status and distribution of the Alaotran gentle lemur Hapalemur griseus alaotrensis
}

\author{
Thomas Mutschler and Anna T.C. Feistner
}

The Alaotran gentle lemur Hapalemur griseus alaotrensis is found only in the marsh vegetation surrounding Lac Alaotra in Madagascar. This habitat is shrinking and becoming fragmented due to conversion to rice cultivation. In addition, lemurs are hunted for pets and food. There is no protected area within their limited range. This paper presents the results of a 6-month field study assessing the distribution, population size and conservation status of the lemur. The population consists of about 7500 animals, split into at least two subpopulations. If no conservation action is taken in the near future, drainage of the remaining 13,000 ha block of marsh vegetation will probably lead to the extinction in the wild of this primate taxon.

\section{Introduction}

The Alaotran gentle lemur Hapalemur griseus alaotrensis, or bandro as it is called locally, is a small $(1.45 \mathrm{~kg}, n=4)$ primate found only in the reed and papyrus beds around Lac Alaotra in Madagascar. Situated between $17^{\circ} 19^{\prime}$ and $17^{\circ} 55^{\prime} \mathrm{S}$, and $48^{\circ} 13^{\prime}$ and $48^{\circ} 39^{\prime} \mathrm{E}$, Lac Alaotra is the largest lake in Madagascar with 22,000 ha open water in the dry season (Nicoll and Langrand, 1989). Although the wetlands of the Alaotran region have been identified as a 'Site d'Intérêt Biologique' (Nicoll and Langrand, 1989), there are no protected areas within this lemur's range. Until recently very little was known of its biology. In July 1969 Petter and Peyrieras (1970) accumulated 20 hours observation of the species in the area of the lake and in 1984 Pollock (1986) spent 3 days studying the animal.

Within the last decade the profile of this taxon has increased as its conservation status has given cause for concern. In 1988 a captivebreeding programme was considered to be of the highest priority (Wharton et al., 1988) as part of the conservation strategy for the lemur. In 1990 the IUCN Lemur Red Data Book classified it as endangered (Harcourt and
Thornback, 1990) and in 1992 the IUCN/SSC Primate Specialist Group listed it as of highest conservation priority in the Lemur Action Plan (Mittermeier et al., 1992). This last classification designated priority status using the following criteria: degree of threat - total population probably between 100 and 1000; taxonomic status - one of a small number of closely related forms that together are clearly distinct from other species; and level of protection - the bandro does not occur in any protected area (Mittermeier et al., 1992).

Since 1990 the Jersey Wildlife Preservation Trust (JWPT) has been working towards the conservation of this lemur. A captive population was set up in 1990 (Durrell, 1991) and breeding occurred in 1993 and 1994 (Steyn and Feistner, 1994; Taylor and Feistner, in press). A poster featuring the lemur has been produced and distributed around the lake, and a series of field studies, covering both wet and dry seasons, has been undertaken (Feistner, 1993, 1994; Mutschler et al., 1994).

The authors' most recent study (FebruaryAugust 1994) provided quantitative information on distribution and population size, and qualitative information on habitat quality. In this paper the implications of these findings 


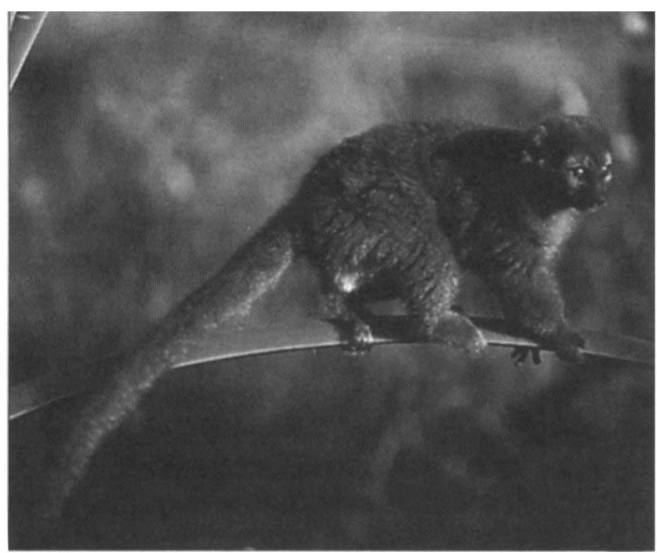

Adult Alaotran gentle lemur or bandro, Hapalemur griseus alaotrenis, on papyrus stem at Lac Alaotra Madagascar (Thomas Mutschler).

for the conservation status of the Alaotran gentle lemur are discussed.

\section{Methods}

\section{Vegetation}

The surface area of the remaining primary marsh vegetation was determined from a map produced in response to the authors' request by the Ministère d'Etat à l'Agriculture et au Developpement Rural. This contemporary map (May, 1994) showed the extent of drainage and cultivation. Ground truthing at several sites established its accuracy. The total surface area of the marsh vegetation, excluding internal lakes, was then calculated. Comparisons between this new map and an earlier one (1990) enabled us to chart changes in the extent of natural vegetation and cultivation. For additional information on bandro and their habitat local fishermen at all sites visited were interviewed.

\section{Animal census}

Surveys of habitat condition and lemur density were made in eight places: at six sites around Lac Alaotra, at Lac Antsomangana and along the Anony River (Figure 1). Because it was not possible to cut transect lines into the dense vegetation, natural borders of the marsh vegetation and existing channels, cut or burnt by fishermen, were used for animal surveying. Surveys were conducted from canoe for a total of $120 \mathrm{~h}$. All observations were carried out by the same team and at the same times each day: $05.00-10.00 \mathrm{~h}$ and $15.30-18.30 \mathrm{~h}$. These were known from previous studies to be times of peak bandro activity. When lemurs were encountered, they were observed for a maximum of $15 \mathrm{~min}$ and the census then resumed. These data were used to calculate the figure 'groups encountered per hour of search'.

\section{Lemur behavioural ecology}

In order to collect information on the behavioural ecology of the lemur, a further $280 \mathrm{~h}$ of observation were made at Andreba, the site of highest animal density. A detailed map of this study site was made using a compass, tapemeasure and range finder (Telinject) and divided into $10 \times 10-\mathrm{m}$ grid squares. Sightings of marked animals (radio collars, Telonics) were plotted on the map and used to determine home-range boundaries (Mutschler et al., 1994). Home-range size was calculated after the borders had been established. For calculation of mean group size, only known groups were included, i.e. groups with marked individuals (radio collars or distinguishing body marks). An absolute density measure for bandro was calculated at this site based on direct observation of known individuals.

\section{Population estimates}

Total population size was calculated by dividing the area of primary marsh vegetation into several sectors, which had different relative densities of lemurs. The surface areas $\left(S_{i}\right)$ of these sectors were multiplied by the absolute animal density measure $(A D)$ and by a relative density measure $\left(r d_{\mathrm{i}}\right)$. Relative density was the encounter rate at other sites compared with the site of highest density (which was scored as 1.0). This gave the population sizes $\left(P S_{i}\right)$ in the various sectors of marsh: $P S_{\mathrm{i}}=S_{\mathrm{i}} \times A D \times$ $r d_{\mathrm{i}}$ The sum of the population sizes in the various sectors gave an estimate of the total population size. 


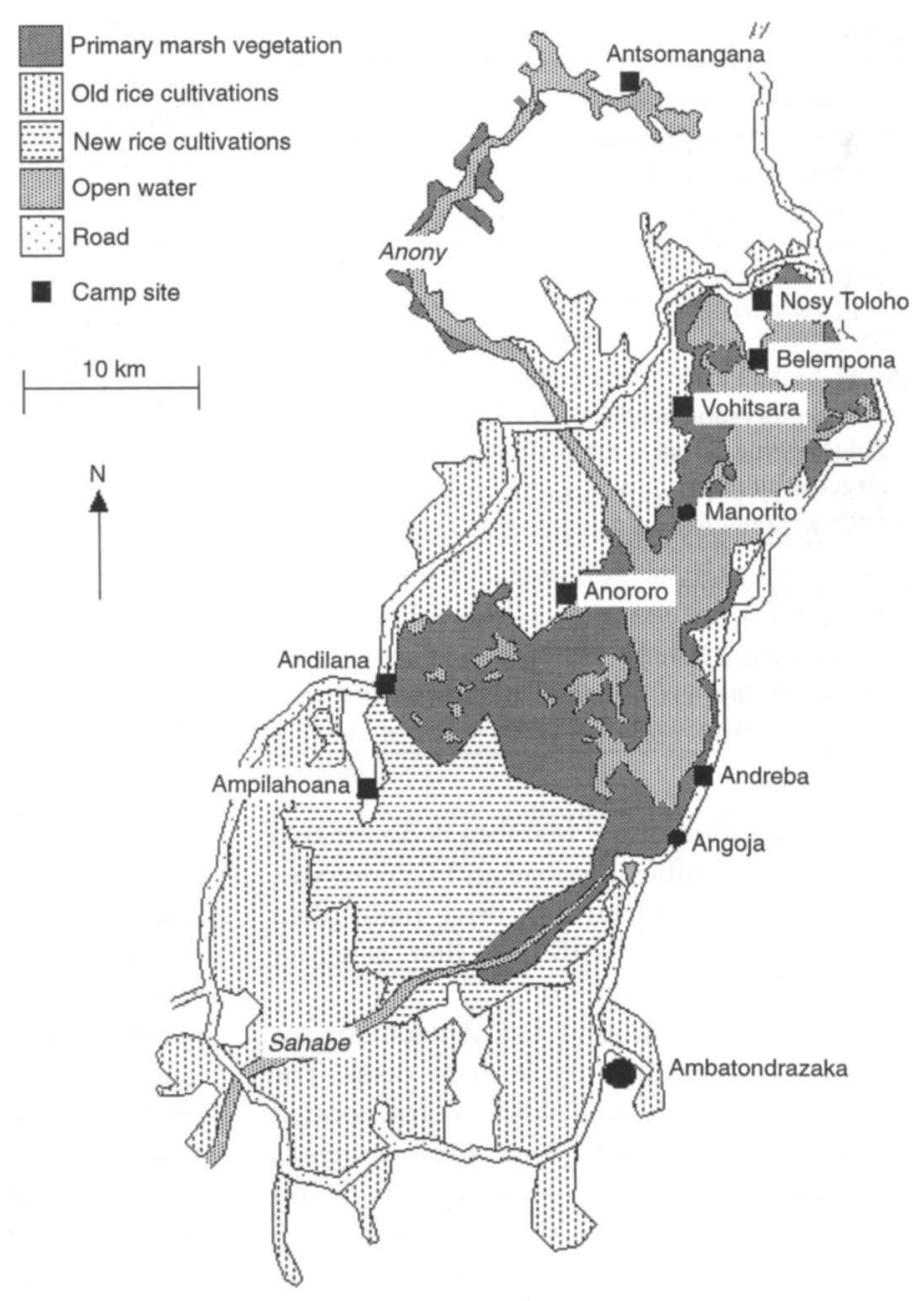

Figure 1. Map of Lac Alaotra and surroundings, based on Carte de Madagascar No. 6 (1:500 000, ed.1990) and updated from a topical map (1994), produced by the Ministère d'Etat à

l'Agriculture et au Developpement Rural. Survey work was undertaken from the camp site bases.

Two measures of relative density were used, resulting in two population estimates. The core area of lemur distribution was split into two parts: a stable climax plant community in the inaccessible interior and a more diverse edge niche with a greater variety of vegetation. Because the interior is likely to support fewer bandro as a consequence of the reduced heterogeneity of the vegetation (M. Pidgeon, unpubl. data), relative density of bandro in interior areas was reduced by 50 per cent. The second and lower population estimate (taking into account reduced relative density in interior areas) was considered more realistic.

\section{Results}

\section{Vegetation}

Old estimates of marsh cover range from 60,000 to 80,000 ha (Moreau, 1987). In 1984 the remaining natural marsh vegetation was reported to cover about 35,000 ha (Nicoll and Langrand, 1989). In the present study, 10 years later, the natural marsh vegetation was reduced by 43 per cent to $c .20,000$ ha. Because bandro are strictly limited to marsh vegetation and have never been observed or reported in cultivated areas, this reduction of natural habitat must have led directly to a decrease in the total population size of the lemur. 
Table 1. Plant communities

Papyrus-mix vegetation
Cyperus madagascariensis
Cyclosorus gongylodes
Echinochloa crusgalli
Polygonum galbrum
Argyreia vahibora
Cuscuta sinensis
Reeds
Phragmites communis
Polygonum galbrum
Argyreia vahibora
Leersia hexandra
Floating vegetation
Nymphaea stellata
Eichhornia crassipes
Salvinia hastata
Leersia hexandra

The vegetation of the marshes is dominated by the plant families Poaceae and Cyperaceae, and can be categorized into three main plant societies (Table 1), with the first category being the most widespread.

The vegetation around Lac Antsomangana is in a narrow belt, only $3-20 \mathrm{~m}$ deep. The composition of the vegetation corresponded largely with the feeding and substrate needs of bandro but its width of only $3-20 \mathrm{~m}$ did not. At the border of the Anony River the vegetation consisted mainly of reeds, but the vegetation was highly degraded and fragmented. A similar degree of fragmentation was found in the vegetation at the north of Lac Alaotra. This area consists of many isolated vegetation patches with a cumulative surface area of about 2000 ha. The triangle AndrebaAndilana-Anororo consisted of a 13,000-ha block of marsh vegetation, including several small internal lakes (Figure 1). This vegetation block was in good condition, although the edges were intensively used by fisherman and papyrus cutters. Using the topical map, 4000 ha of this area were categorized as edge vegetation (all vegetation categories present in substantial amounts) and 9000 ha as dense inner vegetation (uniform papyrus-mix vegetation). South of the triangle all marshes, except some areas along the Sahabe River (5000 ha), have been burnt and drained for rice cultivation. The vegetation belt along the Sahabe River is entirely encircled by rice cultivation and therefore exposed to high pressure from human activity.

\section{Lemur distribution and census}

At Lac Antsomangana, north of Lac Alaotra, and at the border of the Anony River, which connects the two lakes, no lemurs or traces of their activity were found. Local fishermen reported that they had not seen any bandro at Lac Antsomangana since cyclone 'Kamisy' in 1982. In the north of Lac Alaotra a similar situation was found. Between the Anony confluence and Manorito there were no reports of bandro sightings in the last 10 years (1984-94); and between Manorito and Vohitsara there were no sightings in the last 3 years (19911994) (source: local fishermen). Some bandro were observed around the peninsula of Belempona at the extreme north of Lac Alaotra, but their density seemed to be fairly

Table 2. Census data on Hapalemur griseus alaotrensis

\begin{tabular}{|c|c|c|c|c|}
\hline Site & $\begin{array}{l}\text { Census } \\
\text { time (min) }\end{array}$ & $\begin{array}{l}\text { No. of groups } \\
\text { (individuals) }\end{array}$ & $\begin{array}{l}\text { No. groups } \\
\text { per h census }\end{array}$ & $\begin{array}{l}\text { Relative } \\
\text { density }\end{array}$ \\
\hline Antsom.* ${ }^{*}$ Anony & 1170 & $0 \quad(0)$ & 0 & 0 \\
\hline Belempona & 1605 & $6 \quad(12)$ & 0.224 & 0.31 \\
\hline Anororo & 1170 & $10 \quad(30)$ & 0.513 & 0.72 \\
\hline Andilana & 1530 & $12 \quad(33)$ & 0.471 & 0.66 \\
\hline Andreba & 1425 & $17 \quad(42)$ & 0.716 & $1.00 t$ \\
\hline
\end{tabular}

* Antsomangana.

+ Absolute density. 
low (Table 2). Although the cumulative surface area of the vegetation in the north was about $2000 \mathrm{ha}$, the existence of bandro was only confirmed in an area of about 200 ha, with a relative animal density of 0.31 . Both the interviews and the census data indicated that the bandro population living in this area is isolated from the larger southern population.

Within the triangle Andreba-AndilanaAnororo bandro were found at high density (Table 2). The highest density of lemurs was at Andreba and the relative animal density at this site was therefore defined as 1.0. Because all the marshes to the south are drained, except a 5000-ha belt along the Sahabe River, these areas no longer support bandro. The area along the Sahabe was not censused and so there are no hard data on bandro density, nor on the extent of burning, unofficial rice cultivation and habitat fragmentation in this area. However, because interviews with local people indicated similar habitat conditions to those in the northern part of Lac Alaotra, the relative animal density was assumed to be the same as the northern subpopulation.

\section{Total population size}

Mean home range size of the three marked groups of bandro was 2.05 ha (Mutschler et al., 1994). A substantial amount of this area was open water (20-50 per cent, depending on season). This home range size represented the area in which the animals were directly observed. Other observations of study groups that were not marked $(n=7)$ indicated they had comparable home range sizes. In order to determine population density, areas within the marshes that were not occupied by bandro, such as open water, were also taken into account. Four neighbouring groups of lemurs occupied a 15-ha area at the main study site in Andreba, i.e. one group per 3.7 ha of primary marshland. Observed group size varied from two to six individuals with a mean group size of 3.3 individuals ( $n=10$ groups with distinguishing marks). These figures give an absolute density of 0.9 individuals per hectare of primary marsh vegetation at the main study site at Andreba. To estimate the total population size, the absolute density was multiplied by the marsh surface area and modified with the relative density. The results are given in Table 3.

The northern subpopulation had an estimated population size of about 60 animals and along the Sahabe River the estimate was about 1400 animals. In both cases the figures remain unmodified because the census data were accurate and detailed (north) or lacking (Sahabe). For the central triangle we calculated a maximum estimate of 9250 animals. This is based on uniform lemur density throughout the marsh vegetation. However, because the edge vegetation is more diverse then the interior ( $\mathrm{M}$. Pidgeon, unpubl. data) lemur density is likely to be lower there. Therefore the density estimates were reduced by 50 per cent for the area ( 9000 ha) categorized as interior. This gives a population

Table 3. Estimation of total population size of Hapalemur griseus alaotrensis

\begin{tabular}{lccc}
\hline & $\begin{array}{l}\text { Inhabited surface } \\
\text { (ha) }\end{array}$ & $\begin{array}{l}\text { Maximum pop. } \\
\text { size }\end{array}$ & $\begin{array}{l}\text { Estimated pop. } \\
\text { size }\end{array}$ \\
\hline Antsomangana/Anony & indet. & 0 & 0 \\
Northern L.Alaotra & 200 & 60 & 60 \\
Central triangle* & 13,000 & 9,250 & 6,050 \\
$\quad$ edge vegetation & 4,000 & 2,850 & $2,850]$ \\
$\quad$ interior vegetation & 9,000 & 6,400 & $3,200]$ \\
Sahabe River & 5,000 & 1,400 & 1,400 \\
& & & \\
Total & 18,200 & 10,710 & 7,510 \\
\hline
\end{tabular}

*Andreba-Andilana-Anororo. 
estimate of 6050 individuals for the central triangle.

Summation of the subpopulation estimates (Table 3) results in an estimated total population size of 7510 Alaotran gentle lemurs in mid-1994. Although there is a degree of error associated with this figure, we are confident in stating that the total population size is less than 11,000 animals.

\section{Threats}

The threats to the continued survival of Alaotran gentle lemurs are habitat destruction, habitat fragmentation, uncontrolled burning of their habitat and poaching (Pollock 1986; Feistner 1993, 1994). An aerial survey undertaken in October 1993 emphasized the extent of habitat loss. This survey covered the lake's perimeter and five straight-line transects, at regular intervals along pre-scheduled coordinates, were flown across the large southern marsh. Large areas marked on the existing maps as natural vegetation had been replaced by rice cultivation (Feistner, 1994). In addition, the extensive, although localized, use of fire was also clearly seen from the air. Because bandro do not live in cultivated areas, habitat destruction seems to be the most substantial threat. The speed of habitat loss is certainly high, but difficult to calculate, because accurate figures for the past decades are lacking. However, we know that the remaining area of natural vegetation has decreased by 43 per cent over a decade. Half of the southern marshes has already been drained and cultivated. Moreover, we have been told that another stage of large-scale drainage, with the financial support of international organizations, is being considered by the Agriculture Ministry. Because the north, with its population of some 60 animals in isolated and fragmented habitat, is effectively no longer a viable area for bandro, drainage of their last stronghold in the central triangle would have a dramatic negative effect on the survival chances of this lemur. In addition to the drainage of the marshes, fires are lit in the natural vegetation every dry season (Feistner, 1994) and bandro are still captured for food or as pets (Feistner and Rakotoarinosy, 1993), despite existing laws that prohibit these activities with lemurs in Madagascar. Although bandro can reproduce annually and may occasionally have twin infants, at least in captivity (Steyn and Feistner, 1994; Taylor and Feistner, in press), continual and high levels of off-take are unlikely to be sustainable. The number of bandro captured and killed seems to be far from irrelevant, based on the results of interviews with local people (Feistner, 1993, 1994; Feistner and Rakotoarinosy, 1993). The annual animal loss due to this illegal practice seems to be somewhere in the order of several hundred.

\section{Conservation status}

The authors' work, which shows that $H . g$. alaotrensis has a larger population size than previously thought, reduces the total rating used by Mittermeier et al. (1992) by one, but does not change the lemur's position in the category with the highest conservation priority.

Using the new IUCN red list categories (IUCN, 1994) bandro can be classed as critically endangered (Feistner and Mutschler, in prep.).

\section{Discussion}

The authors estimated that $H$. g. alaotrensis had a total population size of $7000-11,000$ animals in mid-1994. This contrasts sharply with the total population size of 100-1000 estimated in the IUCN's Action Plan for Lemur Conservation. However, when the threats the lemur faces are taken into consideration it is clear that total population size is not the primary determinant of conservation status. If the central triangle of remaining marsh vegetation is seriously disturbed - either through penetration and use by local people or, more radically, through conversion to rice paddies by extensive drainage - then the bandro will probably become extinct in the wild in the near future, no matter what total population size is estimated today. It is already clear that 
substantial reductions have occurred and that humans have been the primary agents of change (Mutschler et al., 1995).

Preliminary simulations of extinction risk using VORTEX software (Lacy, 1994) indicate that the northern subpopulation will probably persist for less than 5 years. Further assessments of population viability and the factors affecting it are currently under way (Feistner and Mutschler, unpubl. data).

In addition, it is now known that $H . g$. alaotrensis once occurred at least $35 \mathrm{~km}$ to the north of Lac Alaotra, near Andilamena. After dams were built in 1955 and 1958 the natural vegetation was converted to rice paddies and the lemur disappeared (M. Pidgeon, pers. comm.). The former range of $H . g$. alaotrensis was thus much larger and the existing lemurs are a relict population.

Perhaps the most effective conservation action would be the creation of a protected area encompassing much of the central triangle of primary marsh vegetation between AndrebaAndilana-Anororo. Any such proposal will have to take into account human needs. For example, reeds and papyrus are widely used by the local people. These are renewable resources and, used wisely, could support both human and lemur needs. Effective control of burning and hunting could protect bandro while simultaneously allowing people to use the area for limited vegetation harvest and fishing. Any such conservation action needs to be part of a whole strategy involving community conservation education, rural development, captive breeding and further fieldwork.

The degradation in the fauna and flora of Lac Alaotra has been documented in several studies (Young and Smith, 1989; Wilmé, 1991; Feistner, 1993, 1994; Pidgeon, 1993, 1995). There is little doubt that the removal of vegetation around the lake resulting in silting-up with eroded lateritic soils, the introduction of exotic fish, the reduction in aquatic flora, uncontrolled pesticide use and human resource use are having a large negative impact on the lake's biodiversity (Pidgeon, 1993, 1995). Several species are already in severe decline or locally extinct (e.g. birds: Aythya innotata,
Nettapus auritus, Tachybaptus ruficollis, Platalea alba; fish: Rheocles alaotrensis, Ratsirakia legendrei; plants: Nymphaea stellata [Pidgeon, 1993]). It seems quite likely that H. g. alaotrensis will go the same way if no action is taken in the next few years.

Our studies have made a substantial contribution to knowledge of the little-known bandro and have provided information on which to base a better assessment of its conservation status. Continued habitat destruction and hunting mean that this lemur, the only primate known to be completely dependent on marsh vegetation, is facing extinction.

\section{Acknowledgements}

All the field studies on bandro have been carried out under the JWPT Accord with the Government of Madagascar through the Tripartite Commission. We thank the governmental institutions of Madagascar, especially Mme Celestine of the Direction des Eaux et Forêts, for permission to conduct the studies. The project is funded by Jersey Wildlife Preservation Trust with assistance from Wildlife Preservation Trust Canada. We are grateful to our many Malagasy colleagues who provided logistical help and acted as guides, boatmen and camp-staff. Caroline Nievergelt provided much support and companionship. We are especially indebted to Mark Pidgeon, from whom we learned a great deal and who provided extensive logistical support, advice and access to unpublished data. Both he and Caroline made valued contributions to our field work. Thanks to Mark and Bryan Carroll for useful comments on the manuscript.

\section{References}

Durrell, L. 1991. Notes on the Durrell Expedition to Madagascar September-December 1990. Dodo, Journal of the Jersey Wildlife Preservation Trust, 27, 9-18.

Feistner, A.T.C. 1993. Preliminary Field Study of Hapalemur griseus alaotrensis at Lake Alaotra, Madagascar: A Brief Report. Unpubl. report, Jersey Wildlife Preservation Trust, Jersey.

Feistner, A.T.C. 1994. Dry Season Studies of Hapalemur griseus alaotrensis at Lac Alaotra, Madagascar: A Brief Report. Unpubl. report, Jersey Wildlife Preservation Trust, Jersey.

Feistner, A.T.C. and Rakotoarinosy, M. 1993. Conservation of gentle lemur Hapalemur griseus alaotrensis at Lac Alaotra, Madagascar: Local 
knowledge. Dodo, Journal of the Wildlife Preservation Trusts, 29, 54-65.

Harcourt, C. and Thornback, J. 1990. Lemurs of Madagascar and the Comores. The IUCN Red Data Book. IUCN, Gland and Cambridge.

IUCN 1994. ILCN Red List Categories 1994. IUCN, Gland.

Lacy, R.C. 1994. VORTEX (software): A Stochastic Simulation of the Extinction Process. Chicago Zoological Society and CBSG (SSC/IUCN), Minnesota.

Mittermeier, R.A., Konstant, W.R., Nicoll, M.E. and Langrand, O. 1992. Lemurs of Madagascar: An Action Plan for their Conservation 1993-1999. IUCN, Gland.

Moreau, J. 1987. Madagascar. In African Wetlands and Shallow Water Bodies Directory (eds M. J. Burgis and J. J. Symoens), pp. 595-606. ORSTOM. Paris.

Mutschler, T., Nievergelt, C. and Feistner, A.T.C. 1994. Biology and Conservation of Hapalemur griseus alaotrensis. Unpubl. Report, Jersey Wildlife Preservation Trust, Jersey.

Mutschler, T., Nievergelt, C. and Feistner, A.T.C. 1995. Human-induced loss of habitat at Lac Alaotra and its effect on the Alaotran gentle lemur. International Symposium on Natural and Human-induced Change in Madagascar. Chicago.

Nicoll, M.E. and Langrand, O. 1989. Madagascar: Revue de la Conservation et des Aires Protegées. WWF, Gland.

Petter, J-J. and Peyrieras, A. 1970. Observations écoéthologiques sur les lémuriens Malgaches du genre Hapalemur. Terre et Vie, 24, 356-382.

Pidgeon, M. 1993. Progress Report Project Onjy Further Investigations of the Lake Alaotra Region of
Madagascar with Emphasis on Madagascar Pochard Aythya innotata. Unpublished report, Missouri Botanical Gardens.

Pidgeon, M. 1995. Inventory of the Lake Alaotran Region of Madagascar, with Emphasis on Locating the Madagascar Pochard, Aythya innotata. Unpublished report, Missouri Botanical Gardens and WWF.

Pollock, J. 1986. A note on the ecology and behavior of Hapalemur griseus. Primate Conservation, 7, 97-101.

Steyn, H. and Feistner, A.T.C. 1994. Development of a captive-bred infant Alaotran gentle lemur Hapalemur griseus alaotrensis. Dodo, Journal of the Wildlife Preservation Trusts, 30, 47-57.

Taylor, T.D. and Feistner, A.T.C. In Press. Infant rearing in captive Hapalemur griseus alaotrensis: singleton vs twins. Folia Primatologica.

Wharton, D., Pearl, M. and Koontz, F. 1988. Minutes from a lemur conservation workshop. Primate Conservation, 9, 41-48.

Wilmé, L. 1991. Capture d'un individu vivant de Fuligule de Madagascar, Aythya innotata. Newsletter Working Group on Birds in the Madagascan Region, 1, 7-8.

Young, H.G. and Smith, J.G. 1989. The search for the Madagascar pochard Aythya innotata: Survey of Lac Alaotra, Madagascar October-November, 1989. Dodo, Joumal of the Jersey Wildlife Preservation Trust, 26, 17-34.

Thomas Mutschler and Anna T. C. Feistner, Jersey Wildlife Preservation Trust, Les Augrès Manor, Trinity, Jersey JE3 5BP, Channel Islands, UK. 